\title{
Pulmonary gas transfer in children and adolescents born extremely preterm
}

\author{
Emma Satrell ${ }^{1}$, Ola Røksund ${ }^{1,2}$, Einar Thorsen ${ }^{1}$ and Thomas Halvorsen ${ }^{1,2}$
}

\section{Affiliations:}

${ }^{1}$ Dept of Clinical Science, University of Bergen, Bergen, and

2Dept of Paediatrics, Haukeland University Hospital, Bergen, Norway.

\section{Correspondence:}

E. Satrell, Dept of Paediatrics, Haukeland University Hospital, N-5021, Bergen, Norway.

E-mail: emma.satrellamed.uib.no

ABSTRACT In extremely preterm-born infants, gas exchange takes place in developmentally fetal lungs, disturbing normal acinar growth and differentiation, potentially with long term negative consequences for lung function. The aim was to compare alveolar function in children and adolescents born extremely preterm and at term by measuring diffusing capacity of the lung for carbon monoxide (DLCO). Since this procedure may be challenging for subjects with shortcomings often seen after extremely preterm birth, we also assessed the reproducibility of the method.

DLCO and DLCO adjusted for lung volume (KCO) were measured twice within 2 weeks in two populationbased cohorts born at gestational age $\leqslant 28$ weeks or with birth weight $\leqslant 1000$ g, aged 10.6 years $(n=35)$ and 17.7 years $(n=46)$, and in 81 term-born controls individually matched for sex, age and place of birth.

Reproducibility of DLCO measurements was in the same range for preterm and term-born children and young adults, and coefficients of variation were below $10 \%$ for all subgroups. KCO was significantly reduced with $7.9 \%$ and $7.2 \%$ for the oldest and youngest preterm birth cohorts, respectively.

Reproducibility of DLCO in children and young adults born extremely preterm was adequate. DLCO and KCO were modestly reduced, supporting recent reports suggesting continuing alveolar growth throughout childhood.

@ERSpublications

DLCO and KCO were modestly reduced in children and young adults born extremely preterm http://ow.ly/nWNtx

This article has supplementary material available from www.erj.ersjournals.com

Received: Feb 142012 | Accepted after revision: Nov 062012 | First published online: Nov 222012

Support statement: The major funding institution of this study was the University of Bergen, with minor support from the Paediatric Lung Research Fund, Haukeland University Hospital, Bergen.

Conflict of interest: None declared.

Copyright @ERS 2013 


\section{Introduction}

Over the past 30 years, advances in the care of infants born extremely preterm have markedly increased their prospects of long-term survival [1-3]. Birth in the second trimester of pregnancy implies that gas exchange must take place in developmentally fetal lungs, still in their canalicular or saccular stage $[4,5]$. Proper alveoli have not yet been formed and there is ongoing septation, growth and proliferation of distal respiratory units and capillary networks, which will form the future gas exchange units of the lungs. Human autopsy [6-9] and biopsy [6] studies, as well as animal models [10, 11], suggest that acinar development is altered and characterised by larger, fewer and less complex structures, variable alveolar wall thickness and disturbed vascularisation [8]. Thus, preterm birth disturbs normal acinar development, potentially causing lifelong impairments of gas exchange [5].

Alveolar physiology may be studied by measuring diffusing capacity of the lung for carbon monoxide (DLCO). DLCO is a compound measure, reflecting lung volume, surface area accessible for gas exchange, thickness of the alveolar capillary barrier and pulmonary capillary blood volume. Most studies of subjects born preterm report that DLCO is reduced by $\sim 10 \%$ compared with subjects born at term [12-16]. The standard method for measuring DLCO is the single-breath method, which may be technically challenging for some patient groups and children. The alternative intra-breath method may be easier to perform if the standard single-breath technique fails. However, results from the two techniques have not been compared in studies of children. Monitoring of patients over time requires that true differences in DLCO can be distinguished from differences related to procedural or normal physiological variability. Intersession coefficients of variation (CV) of up to $15 \%$ have been reported in adults [17-19]. To our knowledge, there are no available data on reproducibility in children. In subjects born extremely preterm neurosensory, behavioural and cognitive impairments are common [20-22] and may influence the reproducibility of results when performing complex tasks.

The aims of the present study were to compare lung diffusing capacity and reproducibility of the measurements in population-based birth cohorts of extremely preterm born subjects at 10 and 18 years of age with that of term-born control subjects, matched for sex, age and place. We also wanted to compare the single-breath and intra-breath methods of measuring DLCO.

\section{Methods}

Subjects and study design

All long-term survivors who were born at a gestational age of $\leqslant 28$ weeks or with a birth weight $\leqslant 1000 \mathrm{~g}$ to mothers living within a defined area of the Western Norway Regional Health Authority in the two periods 1991-1992 ( $\mathrm{n}=35)$ and 1982-1985 (n=46) were invited to participate. For each preterm-born participant, the temporally nearest term-born child (gestational age $\geqslant 37$ weeks) of the same sex with a birth weight between 3 and $4 \mathrm{~kg}$ (Norwegian 10th to 90th percentile) was recruited as a control, using relevant hospital birth records as the data source. If that subject declined, the next subject born was approached and so on until a 1:1 control group had been recruited. The purpose of the control group was to reflect the preterm population with respect to relevant attributes except for gestational age at birth. Hence, there were no exclusion criteria except expected inability to perform at the examinations.

Subjects were examined on two different days within a 2-week period in 2001-2002. Clinical data were accessed from hospital charts and from questionnaires. The cohorts have been described in detail elsewhere $[23,24]$ and neonatal data are summarised in table 1 . Mild and moderate/severe bronchopulmonary dysplasia (BPD) was defined as a requirement for supplemental oxygen at $\geqslant 28$ postnatal days or at gestational age $\geqslant 36$ weeks, respectively [25]. No subjects were examined within 2 weeks of a respiratory tract infection. Participants were asked to discontinue asthma medication $24 \mathrm{~h}$ before testing, except for short acting $\beta_{2}$-agonists that could be taken if needed. The Regional Committee for Medical and Health Research Ethics of the Western Norway Health Authority approved the study (no. 287/00-99.2000). Informed written consent was obtained from participating subjects and parents.

\section{Pulmonary function tests}

Lung function measurements were performed using a Vmax 22 (SensorMedics, Yorba Linda, CA, USA) in the sitting position, wearing a nose clip and in accordance with the guidelines of the European Respiratory Society (ERS) [26] and the manuals provided by the manufacturer. The same experienced technician performed all tests, blinded to results obtained in previous test sessions. Measurements of single-breath DLCO (SB-DLCO) were performed by all subjects on both examination days, while measurements of intrabreath DLCO (IB-DLCO) were performed once and only by subjects in the 1982-1985 birth cohort. For comparing methods, data from SB-DLCO and IB-DLCO performed on the same day were used, and only subjects who successfully completed both measurements were included. A true, simple randomisation was 
TABLE 1 Neonatal characteristics of the two preterm born birth cohorts, by severity of bronchopulmonary dysplasia (BPD)

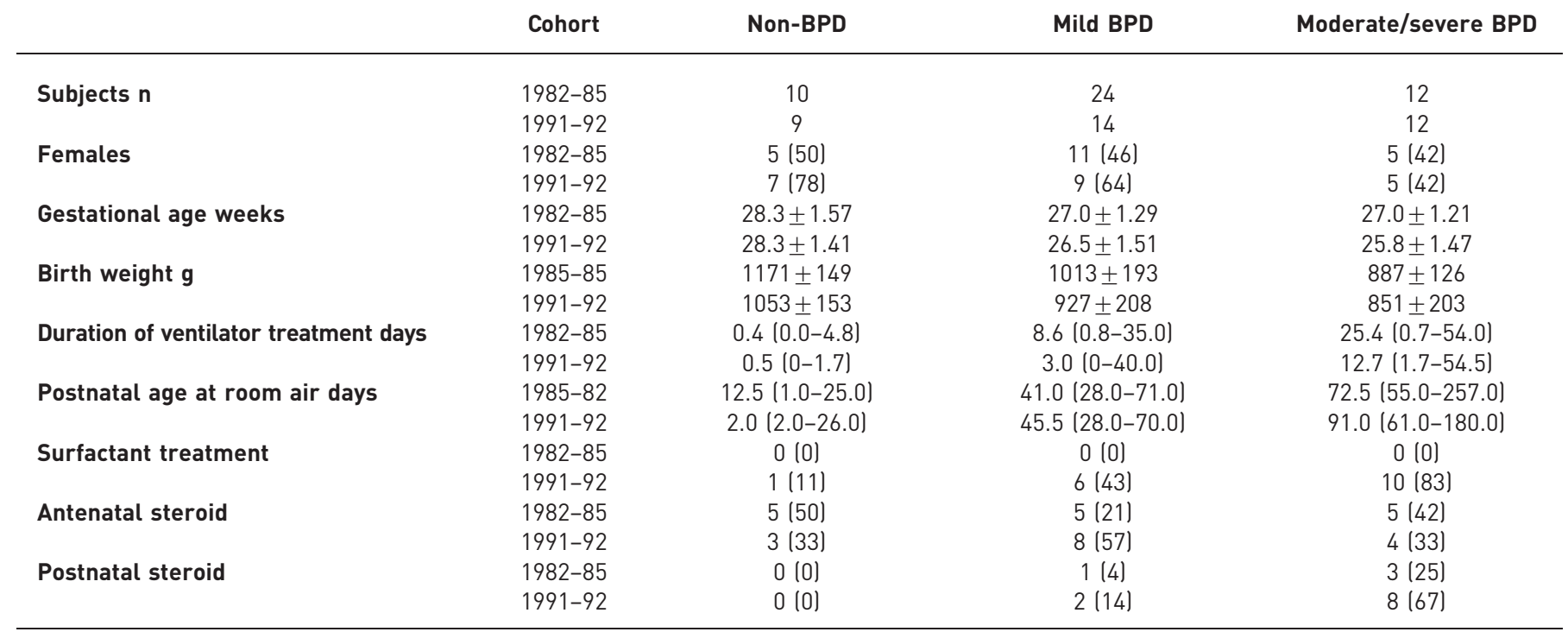

Data are presented as $\mathrm{n}$ ( $\%$ of subgroup), mean \pm SD or median (range), unless otherwise stated. Mild BPD: need for supplemental oxygen at $\geqslant 28$ days of postnatal age; Moderate/severe BPD: need for supplemental oxygen at $\geqslant 36$ weeks of gestational age.

used to determine which of the two methods would be performed first, with a $50 \%$ chance of either method being used before the other. For the study of reproducibility, only subjects who successfully completed SBDLCO measurements on both examination days were included. For the comparison of SB-DLCO between preterm and term-born subjects, only data from matched pairs where both subjects succeeded were included. Measured values were corrected for venous haemoglobin concentration. Details regarding the procedures for the SB-DLCO and IB-DLCO measurements are provided in the online supplementary material.

\section{Statistical analyses}

Means and standard deviations, and medians and ranges were estimated and reported for normally and asymmetrically distributed data, as appropriate. Paired t-tests and McNemar's test were used to compare paired groups, and unpaired statistical methods were used otherwise. The reproducibility of SB-DLCO measurements was determined by calculating the standard deviations of the differences between the two replicate measurements obtained on the two examination days. The standard deviations were used to calculate coefficients of variation $(\mathrm{CV})$, expressed as one standard deviation as a percentage of the average value of the two replicate measurements, and to calculate $95 \%$ limits of agreement, expressed in accordance with BLAND and ALTMAN [27, 28]. One-sample t-tests were applied to assess whether the average difference between replicate measurements differed significantly from zero. Agreement between the single-breath and intra-breath techniques was determined in accordance with BLAND and ALTMAN [27, 28] and the results were expressed as absolute values, as well as percentages of the average of the paired measurements. Reproducibility of the techniques and the agreement between them were visualised by plotting the differences between paired measurements against their average [28]. Regression analyses were used to assess if differences between the preterm and term-born groups were influenced by potential confounding factors (smoking in pregnancy, parental asthma and socioeconomic factors, represented by parental level of education, self-reported smoking and asthma). A test of interaction was used to assess the relationships between preterm and term-born subjects in the two birth cohorts. The study was $90 \%$ powered to detect a difference in forced expiratory volume in $1 \mathrm{~s}$ (FEV1) of at least 7.5\% between preterm and matched termborn control subjects in each of the two birth cohorts, providing a significance level of 0.05 and a standard deviation of $10 \%$ predicted. Data were analysed with SPSS 19 (SPSS, Inc., Chicago, IL, USA) while BlandAltman plots were created with MedCalc version 12.0 (MedCalc Software, Mariakerke, Belgium).

\section{Results}

Subjects

81 (94\%) of the 86 surviving preterm subjects were included, 46 from the 1982-1985 cohort and 35 from the 1991-1992 cohort. One control subject was excluded for medical reasons and replaced by the next consenting subject. Of the 81 primarily invited control subjects, 61 (75\%) responded positively. On average, 
TABLE 2 Baseline demographics of participating preterm and term-born subjects of the two birth cohorts

1982-1985 birth cohort

\begin{tabular}{|c|c|c|c|c|c|c|}
\hline & Preterm & Control $^{\#}$ & p-value & Preterm & Control $^{\circledR}$ & p-value \\
\hline Age years & $17.6 \pm 1.2$ & $17.8 \pm 1.2$ & $<0.001$ & $10.5 \pm 0.4$ & $10.7 \pm 0.4$ & $<0.001$ \\
\hline Height cm & $169.4 \pm 8.1$ & $172.9 \pm 7.5$ & 0.015 & $140.1 \pm 7.9$ & $144.7 \pm 6.3$ & 0.002 \\
\hline Weight kg & $63.4 \pm 15.9$ & $67.6 \pm 11.1$ & 0.220 & $35.1 \pm 12.3$ & $38.3 \pm 6.4$ & 0.202 \\
\hline BMI $\mathrm{kg} \cdot \mathrm{m}^{-2}$ & $21.9 \pm 5.0$ & $22.5 \pm 3.6$ & 0.578 & $17.6 \pm 4.5$ & $18.2 \pm 2.5$ & 0.501 \\
\hline Prenatal smoking exposure & $22(48)$ & $10(22)$ & 0.008 & $13 \overline{(37)}$ & $9(\overline{26})$ & 0.424 \\
\hline FEV1 \% pred & $92.3 \pm 19.3$ & $108.1 \pm 13.8$ & $<0.001$ & $79.2 \pm 9.1$ & $87.0 \pm 8.7$ & 0.001 \\
\hline FEV1 L & $3.3 \pm 0.9$ & $4.0 \pm 0.8$ & $<0.001$ & $1.8 \pm 0.4$ & $2.1 \pm 0.3$ & $<0.001$ \\
\hline FVC \% pred & $102.2 \pm 23.6$ & $111.1 \pm 14.9$ & 0.031 & $87.5 \pm 9.2$ & $92.2 \pm 8.0$ & 0.017 \\
\hline FVC L & $4.0 \pm 1.2$ & $4.6 \pm 0.9$ & 0.002 & $2.1 \pm 0.4$ & $2.4 \pm 0.3$ & $<0.001$ \\
\hline
\end{tabular}

Data are presented as $\mathrm{n}$ (\% of group) or mean $\pm \mathrm{SD}$, unless otherwise stated. Group comparisons were performed with the paired t-test and McNemar's Chi-squared test as appropriate. Asthma was defined as in [24]. BMI: body mass index; FEV1: forced expiratory volume in 1 s; FVC: forced vital capacity. ${ }^{\#}: n=46 ;{ }^{\circ}: n=35$.
1.3 term-born subjects were approached for every preterm subject to establish the complete 1:1 matched control group. All but two participants were Caucasians. Mean \pm SD age was $17.7 \pm 1.2$ years in the $1982-$ 1985 cohort and 10.6 \pm 0.4 years in the 1991-1992 cohort. Height, but not body mass index, was significantly lower in subjects born preterm compared to those born at term (table 2). The number of selfreported smokers was similar in the 1982-1985 preterm and term-born adolescent subgroups, 33\% and $30 \%$, respectively (table 2 ).

\section{Reproducibility of the single-breath technique}

$84(91 \%)$ out of 92 subjects in the 1982-1985 birth cohort and 68 (97\%) out of 70 subjects in the 1991-1992 birth cohort successfully completed SB-DLCO measurements on both examination days. The 10 subjects who failed to complete the measurements were all born preterm. Eight subjects were unable to comply with instructions due to major (cerebral palsy and psychiatric disorders) or minor (cognitive or attention deficit disorders) disabilities and in two subjects there were difficulties with the equipment. The average differences between replicate measurements of SB-DLCO (day 1 minus day 2) were positive for all subgroups, and differed significantly from zero, except for the preterm group of the 1982-1985 birth cohort (table 3). However, the differences did not exceed $6 \%$ of the average of the two measurements for any subgroup. The inspiratory vital capacity on the two test days did not differ significantly, except for term-born controls of the 1991-1992 cohort where the difference was $100 \mathrm{~mL}(\mathrm{p}<0.001)$. The CV for replicate measurements varied from $7.5 \%$ to $9.6 \%$, whereas $95 \%$ limits of agreement, expressed as percentages of the average values of replicate measurements, varied from $14.7 \%$ to $18.7 \%$ (table 3). Figure 1 visualises the reproducibility of SB-DLCO and SB-DLCO per unit of alveolar volume (SB-KCO) in both birth cohorts. Variability did not increase with increasing magnitude of measurements $(\mathrm{p}=0.872$ and $\mathrm{p}=0.281$ for the $1982-1985$ and 1991-1992 cohort, respectively).

\section{Comparison of the single-breath and the intra-breath techniques}

Pairs of successful SB-DLCO and IB-DLCO manoeuvres were obtained for 79 (86\%) subjects in the 1982-1985 birth cohort. Mean \pm SD differences between the two techniques (SB-DLCO minus IB-DLCO) were $0.48 \pm 0.96 \mathrm{mmol} \cdot \mathrm{min}^{-1} \cdot \mathrm{kPa}^{-1}(\mathrm{p}=0.005)$ in the preterm group and $0.32 \pm 0.83 \mathrm{mmol} \cdot \mathrm{min}^{-1} \cdot \mathrm{kPa}^{-1}$ $(\mathrm{p}=0.015)$ in the control group (table 4). Corresponding 95\% limits of agreement between the two techniques were $23.0 \%$ and $17.5 \%$, respectively. Alveolar volume measured with the intra-breath technique was significantly lower than alveolar volume measured with single-breath technique. On average, differences between KCO measured with the two techniques did not differ significantly from zero $(p=0.258$ and $p=0.742$ for the preterm and control group, respectively). The $95 \%$ limits of agreement for KCO measured with the two techniques were $21.3 \%$ for the preterm group and $17.6 \%$ for the control group. The differences between SB-DLCO and IB-DLCO increased with increasing magnitude of the measurements for the preterm group, but not for the controls $(\mathrm{p}=0.003$ and $\mathrm{p}=0.212$ for the preterm and control groups, respectively). No such trend was seen for KCO $(\mathrm{p}=0.202$ and $\mathrm{p}=0.690$ for the preterm and control groups, respectively). 
TABLE 3 Reproducibility of single-breath (SB) diffusing capacity of the lung for carbon monoxide (DLCO) and DLCO per unit of alveolar volume $(\mathrm{Kco})$

Group Day $1 \quad$ Day $2 \quad \begin{gathered}\text { Absolute } \\ \text { difference }\end{gathered} \quad \begin{aligned} & \% \text { difference } \\ & \text { CV }\end{aligned} \begin{gathered}95 \% \text { limits of } \\ \text { agreement }\end{gathered}$

\begin{tabular}{|c|c|c|c|}
\hline \multicolumn{4}{|c|}{$\mathrm{SB}-D \mathrm{LCO} \mathrm{mmol} \cdot \mathrm{min}^{-1} \cdot \mathrm{kPa}^{-1}$} \\
\hline \multirow[t]{2}{*}{ 1982-1985 } & Preterm" & $8.31 \pm 2.08$ & $8.17 \pm 1$ \\
\hline & Control & $9.28 \pm 2.23$ & $8.96 \pm 2$ \\
\hline \multirow[t]{2}{*}{$1991-1992$} & Preterm $^{+}$ & $4.38 \pm 0.94$ & $4.13 \pm 0$ \\
\hline & Control $^{\S}$ & $5.34 \pm 0.63$ & $5.07 \pm 0$ \\
\hline \multicolumn{4}{|c|}{$\mathrm{SB}-\mathrm{Kco} \mathrm{mmol} \cdot \mathrm{min}^{-1} \cdot \mathrm{kPa}^{-1} \cdot \mathrm{L}^{-1}$} \\
\hline \multirow[t]{2}{*}{ 1982-1985 } & Preterm $\#$ & $1.54 \pm 0.24$ & $1.53 \pm 0$ \\
\hline & Control & $1.66 \pm 0.28$ & $1.62 \pm 0$ \\
\hline \multirow[t]{2}{*}{ 1991-1992 } & Preterm $^{+}$ & $1.64 \pm 0.26$ & $1.59 \pm 0$ \\
\hline & Control $^{\S}$ & $1.79 \pm 0.22$ & $1.73 \pm c$ \\
\hline
\end{tabular}

$\begin{array}{llll}0.13 \pm 0.79 & 1.0 \pm 9.2 & 9.6 & 18.7 \\ 0.32 \pm 0.70 & 3.5 \pm 7.7 & 7.5 & 14.7 \\ 0.25 \pm 0.35 & 5.4 \pm 7.4 & 8.2 & 16.1 \\ 0.27 \pm 0.40 & 5.2 \pm 7.2 & 7.7 & 15.1 \\ & & & \\ 0.008 \pm 0.13 & 0.0 \pm 8.9 & 8.4 & 16.4 \\ 0.037 \pm 0.12 & 2.2 \pm 7.0 & 7.0 & 13.8 \\ 0.056 \pm 0.11 & 3.4 \pm 6.9 & 7.1 & 13.9 \\ 0.060 \pm 0.13 & 3.5 \pm 7.7 & 7.6 & 14.9\end{array}$

Data are presented as mean \pm SD. Absolute differences are day 1 minus day 2, while percentage differences are the mean differences for each subgroup expressed as the percentage of mean SB-DLCO on day 1. CV: coefficient of variation expressed as one standard deviation of the difference between measurements on day 1 and day 2 as a percentage of the average of the two measurements; $95 \%$ limits of agreement: 1.96 SD of the differences between the paired measurements, reported as percentage of the mean values of the two measurements. ${ }^{\#}: n=38 ;{ }^{\circledR}: n=46 ;{ }^{+}: n=33 ;^{\S}: n=35$.

\section{Comparison of DLco between preterm and term-born control subjects}

$38(83 \%)$ pairs of preterm/control subjects successfully completed SB-DLCO measurements in the 1982-85 birth cohort and 33 (94\%) pairs in the 1991-1992 birth cohort. SB-DLCO and single-breath KCO were significantly reduced in preterm subjects compared to term-born controls (table 5). Differences between preterm and term-born participants were similar in the two birth cohorts for both measurements (test of interaction, $\mathrm{p}=0.879$ and $\mathrm{p}=0.672$, respectively). The difference between the groups born preterm and at term remained significant after adjustment for potential confounding factors in a backward linear regression model.

Measurements of IB-DLCO were only carried out for subjects in the 1982-1985 birth cohort and successful measurements were obtained in $35(76 \%)$ pairs of preterm/controls. As for measurements obtained with the single-breath technique, mean IB-DLCO $(p=0.003)$ and intra-breath KCO $(p=0.007)$ were significantly lower in the preterm group than the control group (table 5).

Splitting the preterm-born participants into subgroups according to the increasing severity of neonatal $\mathrm{BPD}$, revealed that mean KCO (95\% CI) were 1.52 (1.37-1.67), 1.53 (1.41-1.66) and 1.56 (1.431.69) $\mathrm{mmol} \cdot \mathrm{min}^{-1} \cdot \mathrm{kPa}^{-1} \cdot \mathrm{L}^{-1}$ for non-BPD, mild BPD and moderate/severe $\mathrm{BPD}$, respectively, in the $1982-$ 85 cohort; and $1.53(1.34-1.73), 1.56(1.38-1.75)$ and $1.73(1.60-1.86) \mathrm{mmol} \cdot \mathrm{min}^{-1} \cdot \mathrm{kPa}^{-1} \cdot \mathrm{L}^{-1}$, respectively, in the 1991-1992 cohort.

\section{Discussion}

The study suggests that 10-year-old preterm and term-born children alike are capable of performing the single breath method for measuring DLCO with adequate reproducibility. Data obtained on the first examination day tended to exceed those obtained on the second day. DLCO values obtained with the single breath method exceeded those of the intra-breath method, whereas KCO was similar. Pulmonary diffusing capacity was significantly lower for subjects born preterm compared with control subjects born at term.

\section{Reproducibility of SB-DLCO}

The single-breath technique is the gold standard for measuring pulmonary diffusing capacity. The method is useful in clinical settings, such as in patients with severe lung disease or various forms of vasculitis or autoimmune disease. A recent study suggests that children with diabetes mellitus have significantly reduced DLCO [29]. Pulmonary diffusing capacity is also a relevant variable in a range of research settings. The technique is relatively complex, and may be challenging for children, particularly if cognitive, sensory or physical shortcomings are present. The American Thoracic Society (ATS)/ERS guidelines [30] require the average of two measurements, obtained during the same test session, to be within $10 \%$ of each other, thereby controlling for variability. The variability between sessions will be influenced by the same procedural factors as well as by normal day-to-day physiological variability. The latter is difficult to quantify. To our knowledge, reproducibility of DLCO has not previously been studied in children. Monitoring patients over time requires that findings related to disease are distinguished from expected 

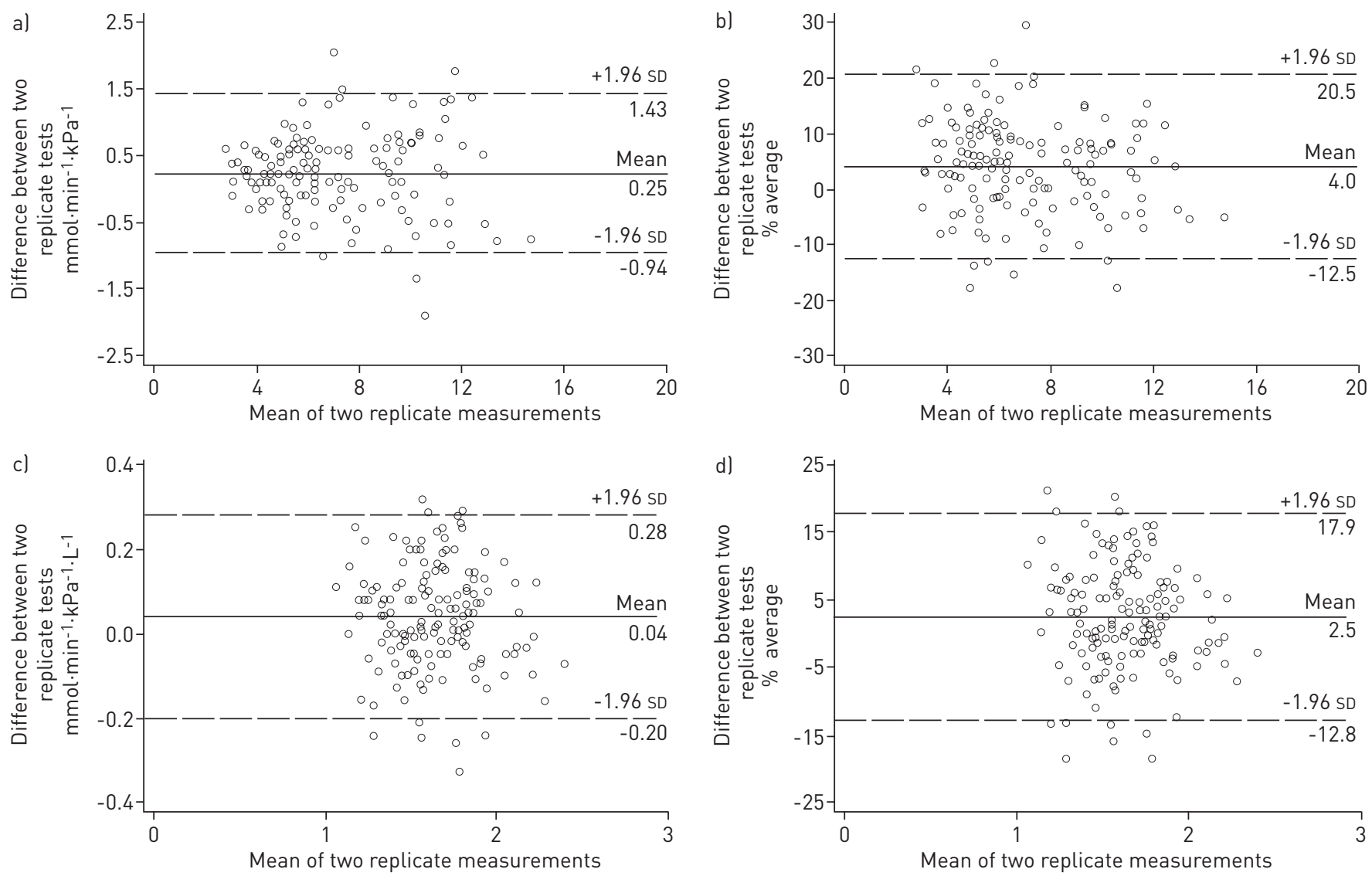

FIGURE 1 Reproducibility of DLCO and KCO for all 152 participating subjects. a) Absolute values of DLCO in $\mathrm{mmol}^{\circ} \mathrm{min}^{-1} \cdot \mathrm{kPa}^{-1}$ and b) DLCO expressed as percentage of the average values. c) absolute values of $K \mathrm{CO}$ in $\mathrm{mmol} \cdot \mathrm{min}^{-1} \cdot \mathrm{kPa}^{-1} \cdot \mathrm{L}^{-1}$ and d) expressed as percentage of the average values. Each point represents the difference between paired measurements of pulmonary diffusing capacity for carbon monoxide (DLCO) and DLCO per unit of alveolar volume (KCO). Values were obtained with the single-breath technique on two different days within a 2 -week period in the same individual, plotted against the mean of the two measurements.

procedural or physiological variability [31]. Surprisingly, in the present study, values of SB-DLCO obtained on the first examination day tended to exceed those of the second examination day for both birth cohorts and for preterm and term-born participants alike, this was also observed when values were adjusted for volume (KCO). We cannot see any obvious explanation for this observation. The average inspiratory volume was relatively similar on the two test days and careful inspection of technical performance did not reveal obvious discrepancies between the two test days. One may speculate that increased anxiety when confronted with the test set-up on day one may have increased the heart rate, which in turn may have increased pulmonary blood flow and thereby DLCO. However, differences were small and less than $6 \%$ of the average SB-DLCO for all subgroups and, thus, below the cut-off set by ATS/ERS of $10 \%$ discrepancies for clinically significant differences [32]. The 95\% limits of agreements for replicate measurements of SB-DLCO observed in the present study suggest that this cut-off is also appropriate for children.

\section{Comparison between the SB-DLCO and IB-DLCo techniques}

Values of IB-DLCO were lower than values of SB-DLCO. This finding was expected, since gas diffusion in the IB-DLCO technique takes place at decreasing lung volumes throughout the exhalation period, while gas diffusion in the SB-DLCO technique takes place at total lung capacity during a $10 \mathrm{~s}$ breath-holding period. Thus, the surface area available for gas transfer is smaller in the intra-breath than in the single-breath manoeuvre, resulting in smaller DLCO values. Alveolar volume $(V A)$ measured with the intra-breath technique was lower for both subgroups, further supporting this theory. Since both DLCO and VA were lower with the intra-breath than the single-breath technique, KCO obtained with the two methods was similar. For DLCO, 95\% limits of agreement between single-breath and intra-breath measurements were in the same ranges as for replicate measurements of SB-DLCO, indicating that the two techniques may be used as substitutes for measurements of DLCO. 
TABLE 4 Comparison of diffusing capacity of the lung for carbon monoxide (DLCO) obtained with the single-breath (SB) technique and the intra-breath (IB) technique in the 1982-1985 birth cohort

\begin{tabular}{|c|c|c|c|c|c|c|c|c|}
\hline $\begin{array}{c}\text { SB-DLCo } \\
{\mathrm{mmol} \cdot \mathrm{min}^{-1}}_{\mathrm{kPa}^{-1}}\end{array}$ & $\begin{array}{c}\text { IB-DLCo } \\
{\mathrm{mmol} \cdot \mathrm{min}^{-1}}_{\mathrm{kPa}^{-1}}\end{array}$ & p-value & SB-VA L & IB-VA L & p-value & $\begin{array}{c}\mathrm{SB}-\mathrm{Kco} \\
\mathrm{mmol} \cdot \mathrm{min}^{-1} \\
\mathrm{kPa}^{-1} \cdot \mathrm{L}^{-1}\end{array}$ & $\begin{array}{c}\text { IB-Kco } \\
{\mathrm{mmol} \cdot \mathrm{min}^{-1}}_{\mathrm{KPa}^{-1} \cdot \mathrm{L}^{-1}}\end{array}$ & $p$-value \\
\hline $8.34 \pm 1.93$ & $7.86 \pm 2.39$ & 0.005 & $5.36 \pm 1.04$ & $5.08 \pm 1.05$ & $<0.001$ & $1.55 \pm 0.22$ & $1.52 \pm 0.25$ & 0.258 \\
\hline $9.35 \pm 2.33$ & $9.03 \pm 2.17$ & 0.015 & $5.63 \pm 1.18$ & $5.42 \pm 1.12$ & $<0.001$ & $1.66 \pm 0.29$ & $1.67 \pm 0.28$ & 0.742 \\
\hline
\end{tabular}

Data are presented as mean $\pm S D$, unless otherwise stated. $p$-values were obtained from paired t-tests, referring to differences between the two methods. VA: alveolar volume; KCO: DLCO per unit of VA. " 36 preterm subjects; ": 43 control subjects were included in the analysis.

\section{Diffusing capacity in preterm versus term-born subjects}

On average, pulmonary diffusing capacity was significantly reduced in subjects born preterm compared with term-born controls, approximately $7-10 \%$ for KCO. These data are in line with most previous reports of significant, but nevertheless relatively modest reductions of pulmonary diffusing capacity after extremely preterm birth $[12,13,33]$. Altogether, $88 \%$ of eligible subjects contributed to the comparisons. There was no trend towards improvement or deterioration for subjects born preterm in the 1990s compared to their peers born in the 1980s. Within the groups born preterm, there were no clear associations between the severity of neonatal BPD and subsequent lung diffusing capacity at follow-up. However, the number of participants in the subgroups was too low to conclude on this issue. Potential relationships between perinatal characteristics, such as BPD, and subsequent measures of pulmonary gas transfer are important questions and should be addressed in future, larger studies.

Pulmonary histopathology in extremely preterm born infants has shown impaired acinar development, fewer and larger alveoli, thickened alveolar-capillary membranes and altered pulmonary capillary structures $[8,34]$. These are fundamental variables for pulmonary gas diffusing capacity [35]. One could, therefore, expect gas diffusing capacity to be similarly affected, a concept that is somewhat challenged by the relatively modest decreases in DLCO reported from the present and previous studies. Similarly modest decreases in maximal exercise capacity have also been reported, further challenging the notion of severe acinar impairments $[36,37]$. When discussing these issues, one must bear in mind that the histopathological understanding is based on animal studies or studies of infants or small children who have died, mostly from their lung disease. Data from older subjects with a more typical pulmonary course have, to our knowledge, not been published, except as one case report $[9,38]$. Thus, to date, there are no studies to support or reject a possible catch-up growth of respiratory units throughout childhood. Recent animal [39, 40] and human [41] studies suggest that alveolarisation may in fact continue to adulthood. These data are encouraging, and may represent a possible explanation for the apparent discrepancies between histopathological findings in infants and physiological findings observed in later life.

TABLE 5 Comparisons between preterm and term-born control subjects regarding diffusing capacity of the lung for carbon monoxide ( $D L C O)$, alveolar volume (VA), and DLCo per unit of VA (KCO)

\begin{tabular}{|c|c|c|c|c|c|}
\hline & Birth cohort & Controls & Preterms & Difference $\left(95 \% \mathrm{Cl}^{\#}\right.$ & p-value \\
\hline \multirow[t]{2}{*}{$\mathrm{SB}-\mathrm{DLCO} \mathrm{mmol} \cdot \mathrm{min}^{-1} \cdot \mathrm{kPa}^{-1}$} & $1982-1985^{+}$ & $9.35 \pm 2.27$ & $8.24 \pm 2.00$ & $-1.11(-1.76$ to -0.46$)$ & 0.001 \\
\hline & $1991-1992^{\S}$ & $5.20 \pm 0.62$ & $4.26 \pm 0.87$ & $-0.94(-1.23$ to -0.65$)$ & $<0.001$ \\
\hline SB-VA L & $1991-1992^{\S}$ & $2.98 \pm 0.32$ & $2.66 \pm 0.49$ & $-0.32(-0.49$ to -0.15$)$ & $<0.001$ \\
\hline \multirow[t]{2}{*}{$\mathrm{SB}-\mathrm{KCO} \mathrm{mmol} \cdot \mathrm{min}^{-1} \cdot \mathrm{kPa}^{-1} \cdot \mathrm{L}^{-1}$} & $1982-1985^{+}$ & $1.66 \pm 0.27$ & $1.54 \pm 0.22$ & $-0.12(-0.22$ to -0.021$)$ & 0.019 \\
\hline & $1991-1992^{\S}$ & $1.76 \pm 0.23$ & $1.61 \pm 0.26$ & $-0.14(-0.24$ to -0.044$)$ & 0.006 \\
\hline IB-Kco mmol $\cdot \mathrm{min}^{-1} \cdot \mathrm{kPa}^{-1} \cdot \mathrm{L}^{-1}$ & $1982-1985^{f}$ & $1.69 \pm 0.28$ & $1.52 \pm 0.25$ & $-0.17(-0.29$ to -0.049$)$ & 0.007 \\
\hline
\end{tabular}

Data are presented as mean + SD, unless otherwise stated. SB: single-breath method; IB: intra-breath method. \#: mean difference between preterm and term-born controls; ${ }^{\top}$ : p-values obtained from paired t-tests, referring to differences between preterms and matched term-born controls; ${ }^{+}: \mathrm{n}=76 ;{ }^{\S}: \mathrm{n}=66 ;{ }^{f}: \mathrm{n}=70$. 


\section{Conclusion}

Reproducibility of measurements of lung diffusing capacity in 10-year-old preterm and term-born children was adequate and similar to that of healthy young adults, represented by the adolescent control subjects in the present study. DLCO obtained with the single breath method exceeded that of the intra-breath method, whereas KCO was similar. Pulmonary diffusing capacity was modestly reduced in preterm compared with term-born control subjects. To what extent perinatal characteristics and catch-up growth of the lung parenchyma may influence later pulmonary gas transfer in these children should be addressed in future studies.

\section{Acknowledgements}

We are indebted to G.E. Eide (Centre for Clinical Research, Haukeland University Hospital, Bergen) for statistical advice and review of the manuscript.

\section{References}

1 Markestad T, Kaaresen PI, Rønnestad A, et al. Early death, morbidity, and need of treatment among extremely premature infants. Pediatrics 2005; 115: 1289-1298.

2 Fellman V, Hellström-Westas L, Norman M, et al. One-year survival of extremely preterm infants after active perinatal care in Sweden. JAMA 2009; 301: 2225-2233.

Modi N. Survival after extremely preterm birth. BMJ 2008; 336: 1199-1200.

Joshi S, Kotecha S. Lung growth and development. Early Hum Dev 2007; 83: 789-794.

Smith LJ, McKay KO, van Asperen PP, et al. Normal development of the lung and premature birth. Paediatr Respir Rev 2010; 11: 135-142.

6 Coalson JJ. Pathology of new bronchopulmonary dysplasia. Semin Neonatol 2003; 8: 73-81.

7 Hislop AA, et al. The effects of preterm delivery and mechanical ventilation on human lung growth. Early Hum Dev 1987; 15: 147-164.

8 De Paepe ME, Mao Q, Powell J, et al. Growth of pulmonary microvasculature in ventilated preterm infants. Am J Respir Crit Care Med 2006; 173: 204-211.

9 Cutz E, Chiasson D. Chronic lung disease after premature birth. N Engl J Med 2008; 358: 743-745.

10 Albertine KH, Jones GP, Starcher BC, et al. Chronic lung injury in preterm lambs. Disordered respiratory tract development. Am J Respir Crit Care Med 1999; 159: 945-958.

11 Coalson JJ, Winter VT, Siler-Khodr T, et al. Neonatal chronic lung disease in extremely immature baboons. Am J Respir Crit Care Med 1999; 160: 1333-1346.

12 Hakulinen AL, Järvenpää AL, Turpeinen M, et al. Diffusing capacity of the lung in school-aged children born very preterm, with and without bronchopulmonary dysplasia. Pediatr Pulmonol 1996; 21: 353-360.

13 Narang I, Bush A, Rosenthal M. Gas transfer and pulmonary blood flow at rest and during exercise in adults 21 years after preterm birth. Am J Respir Crit Care Med 2009; 180: 339-345.

14 Mitchell SH, Teague WG. Reduced gas transfer at rest and during exercise in school-age survivors of bronchopulmonary dysplasia. Am J Respir Crit Care Med 1998; 157: 1406-1412.

15 Vrijlandt EJ, Gerritsen J, Boezen HM, et al. Lung function and exercise capacity in young adults born prematurely. Am J Respir Crit Care Med 2006; 173: 890-896.

16 Welsh L, Kirkby J, Lum S, et al. The EPICure study: maximal exercise and physical activity in school children born extremely preterm. Thorax 2010; 65: 165-172.

17 Hathaway EH, Tashkin DP, Simmons MS. Intraindividual variability in serial measurements of DLCO and alveolar volume over one year in eight healthy subjects using three independent measuring systems. Am Rev Respir Dis 1989; 140: $1818-1822$.

18 Drummond MB, Schwartz PF, Duggan WT, et al. Intersession variability in single-breath diffusing capacity in diabetics without overt lung disease. Am J Respir Crit Care Med 2008; 178: 225-232.

19 Mungall IP, Hainsworth R. Assessment of respiratory function in patients with chronic obstructive airways disease. Thorax 1979; 34: 254-258.

20 Moster D, Lie RT, Markestad T. Long-term medical and social consequences of preterm birth. N Engl J Med 2008; 359: 262-273.

21 Saigal S, Doyle LW. An overview of mortality and sequelae of preterm birth from infancy to adulthood. Lancet 2008; 371: 261-269.

22 Leversen KT, Sommerfelt K, Rønnestad A, et al. Prediction of neurodevelopmental and sensory outcome at 5 years in Norwegian children born extremely preterm. Pediatrics 2011; 127: e630-e638.

23 Halvorsen T, Skadberg BT, Eide GE, et al. Assessment of lung volumes in children and adolescents: comparison of two plethysmographic techniques. Clin Physiol Funct Imaging 2005; 25: 62-68.

24 Halvorsen T, Skadberg BT, Eide GE, et al. Characteristics of asthma and airway hyper-responsiveness after premature birth. Pediatr Allergy Immunol 2005; 16: 487-494.

25 Jobe AH, Bancalari E. Bronchopulmonary dysplasia. Am J Respir Crit Care Med 2001; 163: 1723-1729.

26 Cotes JE, Chinn DJ, Quanjer PH, et al. Standardization of the measurement of transfer factor (diffusing capacity). Report Working Party Standardization of Lung Function Tests, European Community for Steel and Coal. Official Statement of the European Respiratory Society. Eur Respir J 1993; 6: Suppl. 16, 41-52.

27 Bland JM, Altman DG. Statistical methods for assessing agreement between two methods of clinical measurement. Lancet 1986; 1: 307-310.

28 Bland JM, Altman DG. Measuring agreement in method comparison studies. Stat Methods Med Res 1999; 8: 135-160.

29 Scaramuzza AE, Morelli M, Rizzi M, et al. Impaired diffusing capacity for carbon monoxide in children with type 1 diabetes: is this the first sign of long-term complications? Acta Diabetol 2012; 49: 159-164.

30 Macintyre N, Crapo RO, Viegi G, et al. Standardisation of the single-breath determination of carbon monoxide uptake in the lung. Eur Respir J 2005; 26: 720-735.

31 Jensen RL, Teeter JG, England RD, et al. Sources of long-term variability in measurements of lung function: implications for interpretation and clinical trial design. Chest 2007; 132: 396-402. 
Pellegrino R, Viegi G, Brusasco V, et al. Interpretative strategies for lung function tests. Eur Respir J 2005; 26: 948-968. Smith LJ, van Asperen PP, McKay KO, et al. Reduced exercise capacity in children born very preterm. Pediatrics 2008; 122: e287-e293.

34 Coalson JJ. Pathology of bronchopulmonary dysplasia. Semin Perinatol 2006; 30: 179-184.

35 Weibel ER, Federspiel WJ, Fryder-Doffey F, et al. Morphometric model for pulmonary diffusing capacity. I. Membrane diffusing capacity. Respir Physiol 1993; 93: 125-149.

36 Clemm H, Røksund O, Thorsen E, et al. Aerobic capacity and exercise performance in young people born extremely preterm. Pediatrics 2012; 129: e97-e105.

37 Jacob SV, Lands LC, Coates AL, et al. Exercise ability in survivors of severe bronchopulmonary dysplasia. Am J Respir Crit Care Med 1997; 155: 1925-1929.

38 Baraldi E, Filippone M. Chronic lung disease after premature birth. N Engl J Med 2007; 357: $1946-1955$.

39 Burri PH. Structural aspects of postnatal lung development-alveolar formation and growth. Biol Neonate 2006; 89: 313-322.

40 Schittny JC, Mund SI, Stampanoni M. Evidence and structural mechanism for late lung alveolarization. Am J Physiol Lung Cell Mol Physiol 2008; 294: L246-L254.

41 Narayanan M, Owers-Bradley J, Beardsmore CS, et al. Alveolarization continues during childhood and adolescence: new evidence from helium-3 magnetic resonance. Am J Respir Crit Care Med 2012; 185: 186-191. 